\title{
$\mathrm{BMJ}$
}

\section{Comparisons between geographies of mortality and deprivation from the 1900s and 2001: spatial analysis of census and mortality statistics}

\author{
Ian N Gregory, senior lecturer in digital humanities
}

Faculty of Arts and Social Sciences, Furness College, Lancaster University, Lancaster LA1 4YG Correspondence to:

I.Gregory@lancaster.ac.uk

Cite this as: BMJ 2009;339:b3454 doi:10.1136/bmj.b3454

\section{ABSTRACT}

Objectives To examine the geographical relation between mortality and deprivation in England and Wales at the start of the 20th and 21st centuries. To explore the evidence for a strengthening or weakening of this relation over the century and test for relations between the mortality and deprivation patterns of a century ago and modern mortality and causes of death.

Design Census and mortality data for 634 districts from the 1900 s directly compared with interpolated ward level data from 2001.

Setting Census data and national statistics for England and Wales in the 1900s and 2001.

Population Entire population in both periods.

Main outcome measures Standardised mortality ratios for all districts for both periods with additional cause specific ratios calculated for 2001. Deprivation (Carstairs) scores for each district in 2001, with comparable measure created for the 1900s. Correlations and partial correlations between deprivation scores and standardised mortality ratios in the 1900s and 2001 for the 614 districts for which all data were available.

Results The was no evidence of a significant change in the strength of the relation between deprivation and mortality between the start and end of the 20th century. Modern patterns of mortality and deprivation remain closely related to the patterns of a century ago. Even after adjustment for modern deprivation, standardised mortality ratios from the 1900 s show a significant correlation with modern mortality and most modern causes of death. Conversely, however, there was no significant relation between deprivation in the 1900 s and modern mortality for most causes of death after adjustment for modern deprivation.

Conclusions Despite all the medical, public health, social, economic, and political changes over the 20th century, patterns of poverty and mortality and the relations between them remain firmly entrenched. There is a strong relation between the mortality levels of a century ago and those of today. This goes beyond what would have been expected from the continuing relation between deprivation and mortality and holds true for most major modern causes of death.

\section{INTRODUCTION}

The 20th century saw dramatic improvements in patterns of mortality in England and Wales. Age and sex specific mortality rates declined across all ages but particularly among the young (fig 1). In the 1900s the infant mortality rate was 127.6 deaths per 1000 births, $33 \%$ of deaths occurred in the under 5 s, and only $13 \%$ occurred in those aged 75 and over. ${ }^{1}$ By 2001 the infant mortality rate was 5.4 per 1000 births, deaths in those aged under 5 had fallen to less than $1 \%$ of the total, and nearly $65 \%$ of deaths occurred in those aged 75 and over. ${ }^{2}$ Life expectancy rose from 46 for men and 50 for women in the $1900 \mathrm{~s}^{3}$ to 77 for men and 81 for women in $2001,{ }^{4}$ adding an expectation of 31 years of life from birth to both sexes.

These changes are linked to a major change in causes of death. Modern causes are dominated by cancers, which contributed $25.6 \%$ of all deaths in 2001 , ischaemic heart diseases (19.9\%), and stroke (11.0\%). Respiratory diseases are also a major contributor, accounting for $12.7 \%$ of deaths, of which pneumonia caused $6.0 \%$ of the overall total. As table 1 shows, the leading causes of death in the 1900s were different. Classifications were far less well organised, resulting in over half of all deaths being assigned to "other causes." Respiratory diseases were important, pneumonia accounted for $8.2 \%$ of deaths and bronchitis for $7.6 \%$. Cancer was also important but contributed only $5.9 \%$ of deaths. Unsurprisingly, the striking

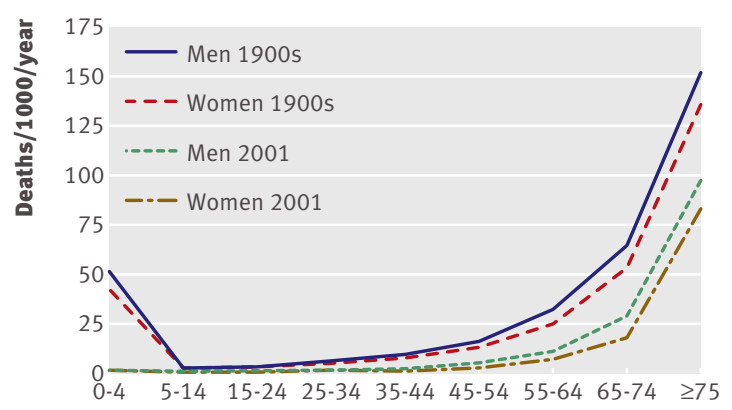

Age (years)

$\overline{\text { Fig } 1 \text { Death rates in England and Wales by age and sex in the }}$ 1900s and $2001^{1}$ 
feature is the numbers of infectious and parasitic diseases, which accounted for nearly a fifth of deaths. Many of these were in the young, with over $90 \%$ of deaths from diarrhoea and dysentery, measles, and whooping cough being among those aged under 5 . The other noticeable feature is the lack of heart disease as a cause of death. The only major cause of death linked to heart disease was "rheumatic fever and rheumatism of the heart," which accounted for only $0.5 \%$ of deaths and was itself an infectious disease.

The experience of poverty has also changed dramatically over the century. In the 1900 s poverty was usually an absolute concept, which meant, according to Rowntree, that the income of an individual or family was not "sufficient to obtain the minimum necessaries for the maintenance of mere physical efficiency." Advances in standards of living and the growth of the welfare state now mean this absolute definition is rarely used; instead poverty tends to be seen as a relative concept. Relative poverty is usually expressed by comparing the individual's income or deprivation with that experienced by the society as a whole. Thus people might be defined as living in relative poverty if "they cannot obtain, at all or sufficiently, the conditions of life ... which allow them to play the roles, participate in the relationships and follow the customary behaviour which is expected of them by virtue of their membership of society." 6

There is a longstanding relation between poverty and mortality. ${ }^{78}$ Few studies have looked at whether this has changed or remained stable over the long term. In Dorling et al's study of inner London, however, they used Charles Booth's survey of poverty in inner London to compare mortality and poverty in the 1890s and the 1990s. ${ }^{9}$ They showed clear links between an area's modern mortality and its poverty in the past.

I explored the link between deprivation and mortality for areas in the 1900s and today for the whole of England and Wales. I used mortality data and a

\begin{tabular}{lccc}
\hline Table 1 | Leading causes of death* in England and Wales in the 1900s & \\
Cause & Total deaths & \% of total deaths & Rate per 10 000 people \\
Other causes & 2659781 & 50.67 & 778.2 \\
\hline Pneumonia & 428747 & 8.17 & 125.4 \\
\hline Bronchitis & 398315 & 7.59 & 116.5 \\
\hline Cancer & 309141 & 5.89 & 90.4 \\
\hline Phthisis (not otherwise defined) & 232285 & 4.43 & 68.0 \\
\hline Violence & 195486 & 3.72 & 57.2 \\
\hline Diarrhoea and dysentery & 193862 & 3.69 & 56.7 \\
\hline Pulmonary tuberculosis & 164600 & 3.14 & 48.2 \\
\hline Measles & 105481 & 2.01 & 30.9 \\
\hline Whooping cough & 94548 & 1.80 & 27.7 \\
\hline Influenza & 73176 & 1.39 & 21.4 \\
\hline Diphtheria & 60924 & 1.16 & 17.8 \\
\hline Tuberculous meningitis & 59965 & 1.14 & 17.5 \\
\hline Other tuberculous diseases & 57367 & 1.09 & 16.8 \\
\hline
\end{tabular}

*Includes only causes that accounted for over $1 \%$ of deaths. measure of deprivation for the 1900s and compared these with mortality and deprivation measures for 2001.

\section{METHODS}

The Office for National Statistics published modern mortality and deprivation data for England and Wales in 2001. VS4D data give deaths by age and sex; VS4DL data give common causes of death using ICD-10 (international classification of disease, 10th revision) codes. ${ }^{10}$ The census provides population data including deprivation indicators. ${ }^{11}$ Similar data are available from the registrar general's decennial supplement, which provides mortality data for the decade from 1901 to $1910,{ }^{1}$ and the censuses of $1901^{12}$ and 1911. ${ }^{13}$ The most important contrast between these datasets taken from either end of the 20th century is that the 2001 data are available for 8850 census area statistics wards while the 1900s data were published for only 634 registration districts (excluding the Isles of Scilly). To compare mortality and deprivation at these two dates I developed a deprivation index for the 1900s that is similar to the modern Carstairs index and interpolated 2001 data onto the same administrative geography as the 1900 s data to allow direct comparisons.

The use of deprivation indices based on census data is well established. Several different measures have been used, including the Carstairs, Townsend, and Jarman indices. While these are based on slightly different variables they are closely correlated with each other. ${ }^{14}$ The Carstairs index is one of the simplest and is an aggregate of standardised data from four census variables: overcrowded housing, low social class, male unemployment, and households without a car. ${ }^{15}$ For recent censuses, which means 1971 onwards, there is a strong association between deprivation defined using this approach and mortality, represented with standardised mortality ratios to remove the impact of differing age and sex distributions. ${ }^{16} 17$

Measuring deprivation for a century ago is more problematic. In their London study, Dorling et $\mathrm{al}^{9}$ used data from Charles Booth's survey to provide a proxy for social class; this is limited to just social class and is available only for inner London. I calculated a deprivation index using variables similar to those used in the Carstairs index for the whole of England and Wales in the 1900s. This involved the use of three measures: overcrowded housing, low social class, and unemployment. The 1901 census provides data on overcrowded housing at registration district level. These data can be used to calculate the number of people living at more than 1.5 people a room in "tenements" of four rooms or less, with tenements of this size being used as the denominator. This gives a measure of overcrowded housing that is similar to the modern definition, which uses people living at more than 1.0 a room over the whole population. Censuses before the first world war did not publish data on social class, though occupational data from the 1911 census can be used to calculate the number of men working in 
unskilled occupations for each registration district as a proportion of economically active males aged 10 and over. ${ }^{18}$ Unemployment is more problematic as it was not counted by the census. An alternative is provided by the Poor Law Commission, which was responsible for the administration of poor relief, a precursor of modern unemployment benefit. The number of able bodied people on "indoor relief" (people who were in the workhouse because they were unable to support themselves) is available for 1 January 1901. It was published for poor law unions, which were closely related to the registration districts used by the census and thus provides a variable that corresponds to unemployment. The denominator was the total population.

This gave three variables that can be claimed to be the historical counterparts of three of the four measures used by the Carstairs index. The fact that the variables used are not direct equivalents of the modern Carstairs variables is relatively unimportant because, as stated above, there are major differences between the experience of deprivation in the 1900 s compared with today. Unfortunately there is no equivalent measure for the fourth variable, households without a car. Nevertheless, converting the three variables into z scores and summing them does provide a deprivation measure for the 1900s. (A z score measures how many SDs from the mean a value lies. It is calculated by subtracting the value from the mean and dividing this by the $\mathrm{SD}$. A value of 0.0 is exactly on the mean, 1.0 is $1 \mathrm{SD}$ above the mean, 2.0 is $2 \mathrm{SD}$ above the mean, and so on. Values that lie below the mean will have negative $\mathrm{z}$ scores. Thus a district with a $\mathrm{z}$ score for unemployment of 1.5 has a rate that is $1.5 \mathrm{SD}$ above the average unemployment rate.) This was available for 614 of the 634 registration districts; the differences between 1901 registration districts, 1911 registration districts, and 1901 poor law unions meant that scores could not be calculated for the other 20 .

All of the data had to be standardised on to a single set of administrative boundaries to allow direct comparisons between the 1900s and 2001. To do this I used a geographical information system, which is effectively a form of database that stores the statistical data along with the boundaries of the administrative units they refer to. Modern data are available from UKBorders at the University of Edinburgh, while the historical data are available though the Great Britain Historical Geographical Information System. ${ }^{19}$ Having the data in this form allowed calculation of the intersection between the 2001 census area statistics wards and the registration districts and poor law unions from the 1900s. This enabled me to "re-district" the modern data on to registration districts. ${ }^{20}$ The resulting data are estimates that might contain error, but the degree of aggregation that they contain, with an average of 13 wards per registration district, means that the impact of this will be small. In this way I constructed directly comparable measures of area based mortality and deprivation from the beginning of the 20th and 21st centuries.

\section{RESULTS}

Figure 2 shows the spatial patterns of deprivation and mortality in the 1900s. In both cases I used population fifths to divide the data into classes so that each shade contains $20 \%$ of the population. The patterns seem broadly similar: the highest rates of deprivation and mortality were found in urban and industrial areas such as inner London, south Wales, Birmingham, Liverpool, Manchester, Sheffield, and the north east. Low rates are a primarily rural phenomenon, although low mortality rates tended to be concentrated in the south and east of England whereas low deprivation scores are more evenly distributed around the country. Calculation of a Pearson product moment correlation coefficient between the deprivation index and the standardised mortality ratios for the 614 registration districts for which all data were available gave a coefficient of $r=0.503(\mathrm{P}<0.001)$. This tells us that there was a positive strong relation between mortality and deprivation across England and Wales in the 1900 s. It also confirms that the 1900s deprivation index developed here is capable of being a predictor of mortality.

Figure 3 shows Carstairs scores and standardised mortality ratios for 2001 using 1900s registration districts. The pattern of deprivation seems similar to the pattern in the 1900s: high rates are concentrated in urban and industrial areas, except that these have spread out, particularly in what is now the M62 motorway corridor running from Liverpool through Manchester and Sheffield to Hull. The modern mortality map seems superficially to be noticeably different from the 1900s map. On closer inspection, however, urban and industrial areas have high rates at both dates. The main difference is that in 2001 there are several rural areas that have high standardised mortality ratios and the concentration of low standardised mortality ratios in the south east seems to have disappeared. The Pearson's product moment correlation coefficient between mortality and deprivation with these units is $r=0.497(\mathrm{P}<0.001)$. For comparisons, the ward level correlation between standardised mortality ratios and Carstairs scores in 2001 was 0.466 while the correlation between standardised mortality ratios and Townsend scores at this level was $0.428 .{ }^{21}$ These suggest that neither the aggregation required to compare the two periods nor the choice of the Carstairs index compared with a different measure has had a major impact on the results. Figure 4 shows scatter plots of the registration district level relation between deprivation and mortality at the two dates. Given the changes in the deprivation measures, the similarity in the correlations, $r=0.503$ and $r=0.497$ in the 1900 s and 2001, respectively, suggest that there has been little change in the strength of this relation over the course of the century.

As the populations of administrative areas vary widely, one approach to exploring inequality is to compare the $10 \%$ of the population living in areas with the highest rates to the $10 \%$ living in areas with the lowest rates. Fifths that contain $20 \%$ of the population can also 


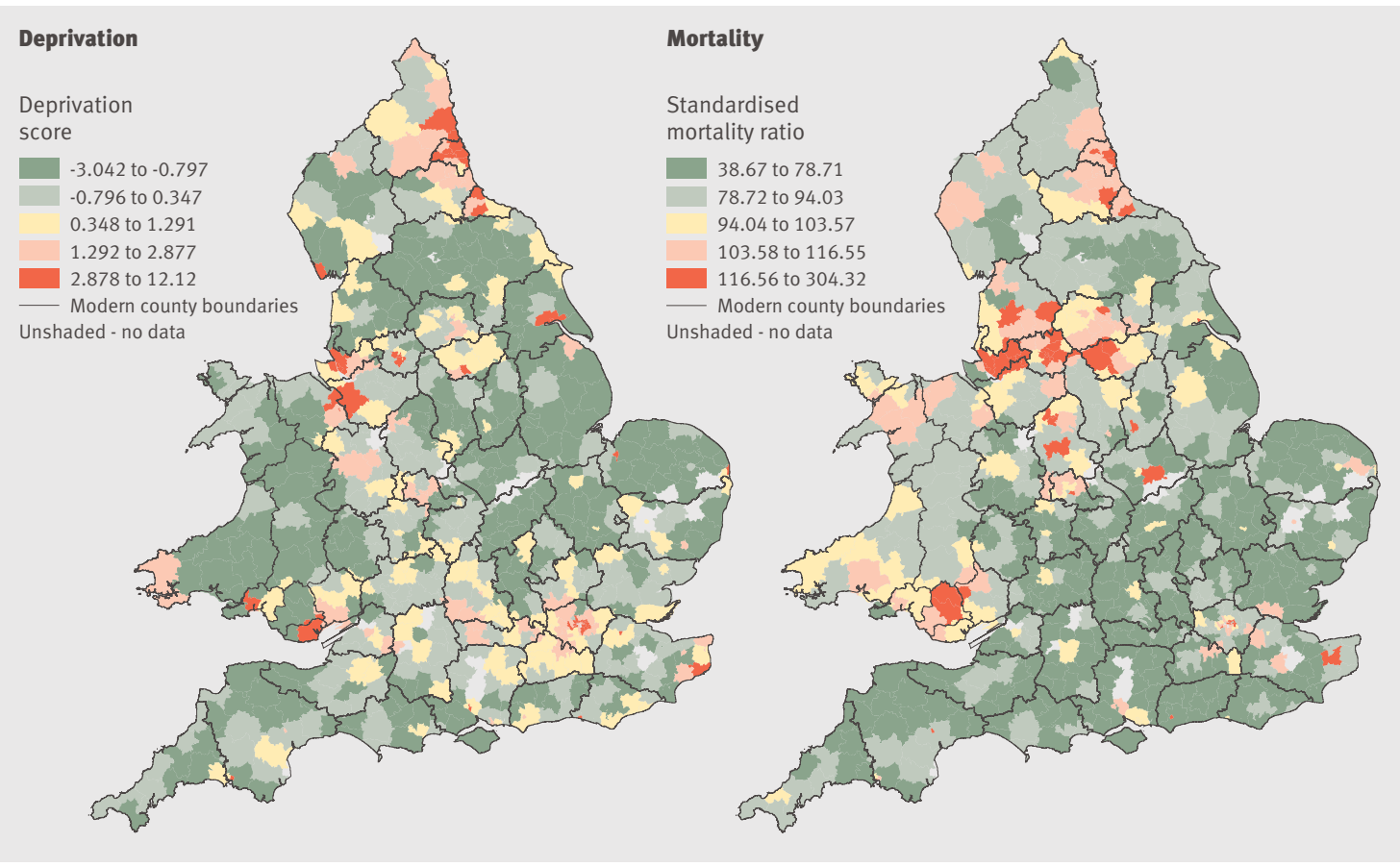

Fig 2 | Deprivation and mortality in the 1900s. Class intervals determined from population fifths from 1901. Modern county boundaries superimposed on 1900 s registration districts to assist orientation

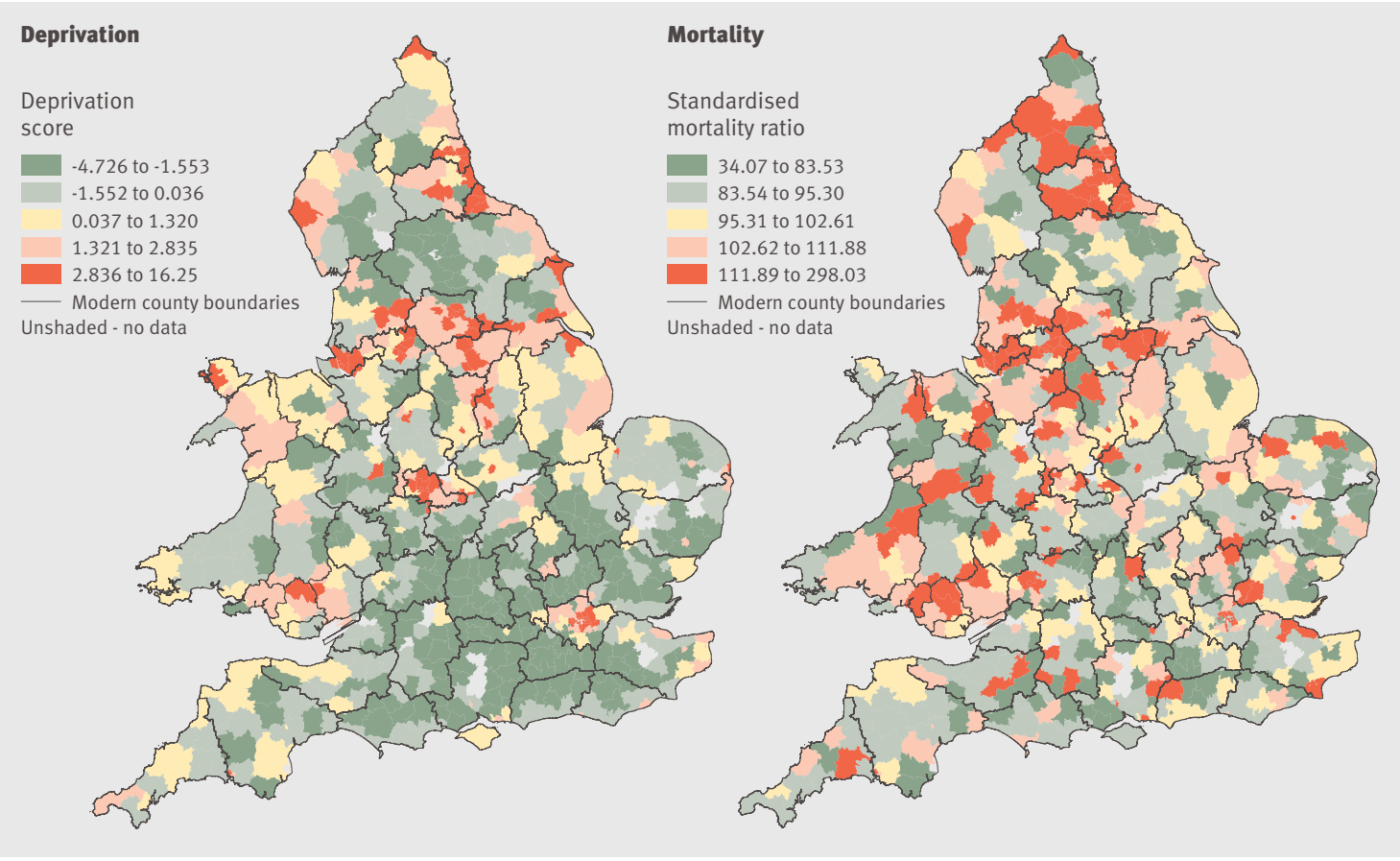

Fig 3 Deprivation and mortality in 2001. Data interpolated from census area statistics wards onto registration districts for the 1900s. Class intervals determined from population fifths from 2001. Modern county boundaries superimposed on 1900 s registration districts to assist orientation

be used, giving a measure across a broader range that is consequently less susceptible to extreme values. Table 2 compares the standardised mortality ratios of the areas containing the best and worst population 10ths and fifths in the 1900s and 2001 for mortality and deprivation. In 2001 the average standardised mortality ratio, weighted by population, of the population 10th with the lowest mortality rates was 75.6 while the average for the highest 10th was 135.5. Thus in 2001 the $10 \%$ of the population living in the highest mortality areas had mortality rates that were 1.79 times higher than the $10 \%$ living in areas with the 
Table 2 Inequality in mortality and deprivation in the 1900s and 2001. Figures are standardised mortality ratios

\begin{tabular}{lccc}
$\begin{array}{l}\text { Date } \\
\text { Mortality }\end{array}$ & Lowest 10th (5th) & Highest 10th (5th) & Ratio of highest to lowest \\
\hline 2001 & $75.6(80.9)$ & $135.5(126.1)$ & $1.79(1.56)$ \\
\hline $1900 \mathrm{~s}$ & $70.4(74.2)$ & $144.2(132.9)$ & $2.05(1.79)$ \\
\hline $\begin{array}{c}\text { Deprivation } \\
2001\end{array}$ & $89.0(89.1)$ & $121.2(113.1)$ & $1.36(1.27)$ \\
\hline $1900 \mathrm{~s}$ & $89.4(92.0)$ & $124.0(118.7)$ & $1.39(1.29)$
\end{tabular}

lowest rates. In the 1900s the average for the highest 10th was 2.05 times higher than the lowest 10th. This shows that the morality gap between the best and worst areas had narrowed over the century because both the best and worst values became less extreme, a pattern that is also found with population fifths. The worst deprivation 10th in 2001 had an average standardised mortality ratio 1.36 times higher than the best, in the 1900 s this ratio was 1.39 . With fifths these values are 1.27 and 1.29. Together these show that, while the mortality gap might have narrowed over the century, the relation between the extremes of deprivation and mortality is as strong today as it was a century ago.

Thus there seems to be a continuing relation between mortality and deprivation. The next question is whether the spatial pattern of mortality and deprivation in the 1900 s can be used to predict modern patterns. Comparing standardised mortality ratios in the 1900s with those in 2001 gives a correlation coefficient of $r=0.414(\mathrm{P}<0.001)$, while comparing the deprivation scores gives a correlation coefficient of $r=0.578$ $(\mathrm{P}<0.001)$ (fig 5). This confirms the patterns suggested by figures 2 and 3 -namely, that strong relations between patterns of mortality and deprivation have persisted over the course of the century.

Table 3 focuses on how the extremes of deprivation and mortality in the 1900 s relate to mortality today. The areas with the lowest and highest 10ths and fifths of mortality in the 1900s still have low and high mortality rates in 2001 . While table 2 showed that in the 1900 s the highest mortality 10th had rates 2.05 times higher than lowest mortality 10th, the mortality ratio between these areas had narrowed to being a more modest 1.38 by 2001 ( 1.30 at fifth level). The impact of 1900s deprivation is also interesting because in 2001 areas with the lowest deprivation scores in the 1900s have an average standardised mortality ratio of 97.2 (98.1 at fifth level), suggesting that areas that were affluent 100 years ago do not now have mortality rates that are significantly better than other areas. By contrast, areas with the highest deprivation scores in the 1900s still have high standardised mortality ratios today,

Table 3 | Inequality in modern (2001) mortality based on mortality and deprivation in 1900s. Figures are standardised mortality ratios

\begin{tabular}{lccc} 
& Lowest 10th (5th) & Highest 10th (5th) & Ratio of highest to lowest \\
\hline Mortality in 1900s & $90.8(90.8)$ & $125.4(118.1)$ & $1.38(1.30)$ \\
\hline Deprivation in 1900s & $97.2(98.1)$ & $116.6(108.8)$ & $1.20(1.11)$ \\
\hline
\end{tabular}
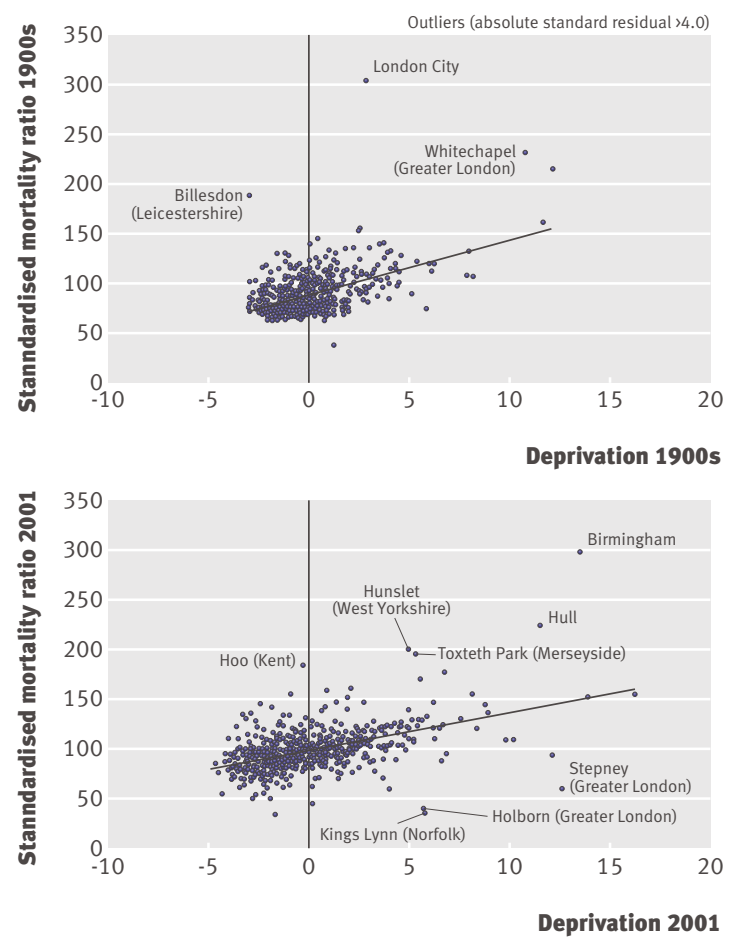

Fig 4 | Relation between deprivation and mortality in the 1900 s and 2001. Outliers are shown for names of 1900 s registration districts with the modern county in parentheses where appropriate

although at 116.6 (or 108.8), this is less pronounced than the impact of high 1900 s mortality at 125.4 (or 118.1).

Given the results already presented, it could be that modern mortality is related to the mortality of the past only because the geography of deprivation has remained largely constant and mortality continues to be strongly related to deprivation. This would mean that the relation between mortality in 2001 and the 1900 s could be explained by inertia in deprivation patterns. To test this, I used partial correlation coefficients to explore whether modern standardised mortality ratios are related to either mortality or deprivation in the 1900s, controlling for the impact of modern deprivation. This gave partial correlation coefficients of $r=0.160 \quad(\mathrm{P}<0.001)$ for $1900 \mathrm{~s}$ mortality, but only -0.016 for 1900 s deprivation $(\mathrm{P}=0.690)$.

Table 4 summarises the correlation coefficients given so far and also includes all of the other relations between variables. Taken together these suggest that mortality and deprivation continue to be closely linked and, in addition, that the mortality patterns of a century ago are still related to today's mortality patterns in a way that cannot simply be explained by inertia in deprivation patterns. Deprivation in the 1900 s does not seem to be related to modern mortality once modern deprivation is controlled for. One possible explanation for the lack of a significant result for deprivation is that the impact of deprivation in the 1900s on modern mortality seems pronounced in deprived areas but not in affluent ones (table 3 ). 
Table 4 | Pearson's product moment correlation coefficients between variables. All data have been standardised on 1900 s registration districts unless otherwise stated

\begin{tabular}{|c|c|c|c|}
\hline Variable 1 & Variable 2 & Controlled for & $r$ \\
\hline Deprivation 1900s & Mortality $1900 \mathrm{~s}$ & - & $0.503^{*}$ \\
\hline Deprivation 2001 & Mortality 2001 & - & $0.497^{*}$ \\
\hline Deprivation 2001 (ward level) & Mortality 2001 (ward level) & - & $0.466^{*}$ \\
\hline Mortality $1900 \mathrm{~s}$ & Mortality 2001 & - & $0.414^{\star}$ \\
\hline Deprivation 1900s & Deprivation 2001 & - & $0.578^{\star}$ \\
\hline Mortality $1900 \mathrm{~s}$ & Deprivation 2001 & - & $0.612^{\star}$ \\
\hline Deprivation 1900s & Mortality 2001 & - & $0.276^{\star}$ \\
\hline Mortality $1900 \mathrm{~s}$ & Mortality 2001 & Deprivation 2001 & $0.160^{*}$ \\
\hline Deprivation 1900s & Mortality 2001 & Deprivation 2001 & -0.016 \\
\hline Deprivation 1900s & Deprivation 2001 & Mortality 2001 & $0.528^{*}$ \\
\hline Mortality $1900 \mathrm{~s}$ & Deprivation 2001 & Mortality 2001 & $0.514^{\star}$ \\
\hline
\end{tabular}

There is therefore good evidence that mortality today is strongly related to the mortality and deprivation conditions of a century ago and that this is not simply because of inertia in patterns of poverty. This poses the question of which modern causes of death are most strongly correlated with conditions 100 years ago. Table 5 correlates standardised mortality ratios of the 14 modern causes of death given in VS4DL data with mortality and deprivation in the past by using Pearson's product moment correlations and partial correlations that take modern deprivation into account. Unsurprisingly the 13 disease based causes are positively related to overall modern mortality and all but bowel cancer, breast cancer (women only), and

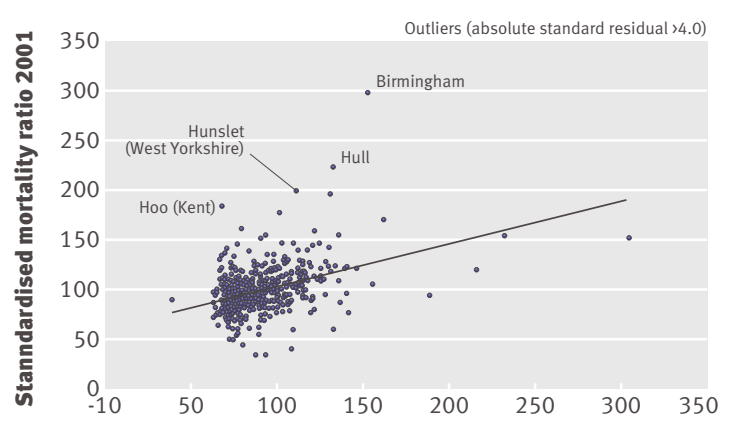

Stanndardised mortality ratio 1900 s

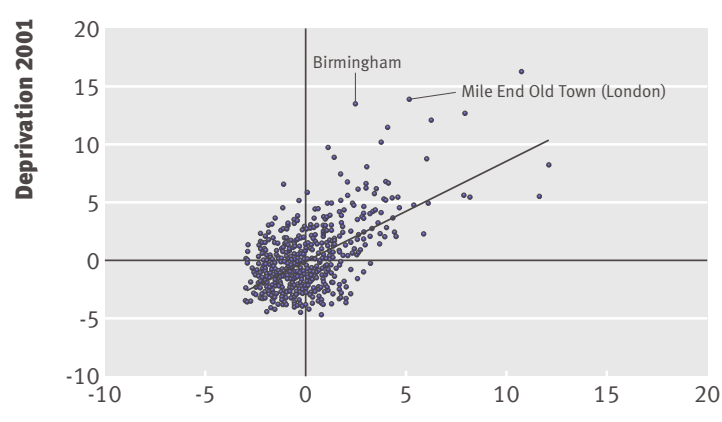

Deprivation 1900s

Fig 5 | Relation between the 1900s and 2001 for standardised mortality ratios and deprivation. Outliers are shown for names of 1900 s registration districts with the modern county in parentheses where appropriate prostate cancer (men only) are positively correlated with modern deprivation. Vehicle accidents, the only non-disease cause, show quite a different pattern; they are not significantly related to overall mortality and are negatively related to modern deprivation. The disease based causes are also strongly related to conditions in the past; the only causes not positively related to mortality or deprivation in the 1900 s are breast and prostate cancers, which are not related to either, and bowel cancer and stroke, which are not related to 1900s deprivation. Again, vehicle accidents are exceptional, being negatively related to both.

The pattern becomes more complicated when conditions in the 1900s are compared with the present causes with adjustment for the effects of modern deprivation. With the continuing exceptions of breast and prostate cancers, all the given classes of cancer are positively related to $1900 \mathrm{~s}$ standardised mortality ratios but only lung cancer is positively related to 1900 s deprivation and even here the relation is weak at $r=0.105$. Diabetes and all diseases of the circulatory and respiratory systems are positively related to 1900 s mortality, albeit that stroke $(r=0.081, \mathrm{P}=0.046)$ and pneumonia $(r=0.095, \mathrm{P}=0.019)$ are significant only at the $\mathrm{P}<0.05$ level. This contrasts sharply with 1900s deprivation, which shows only one weak positive correlation in these causes (with pneumonia, $r=0.086, \mathrm{P}=0.034$ ), and there are instead significant negative relations with diseases of the circulatory system $(r=-0.105, \mathrm{P}=0.009)$ and ischaemic heart disease $(r=-0.131, \mathrm{P}=0.001)$. Again, vehicle accidents show negative relations with both mortality and deprivation in the 1900s. Therefore it seems that once modern deprivation is taken into account the patterns of most major modern causes of death can be predicted from mortality in the past but not from the deprivation of the past.

\section{DISCUSSION}

The 20th century has seen a dramatic decline in mortality, but, despite this, the link between mortality and deprivation across England and Wales remains as strong today as it was a century ago. Geographical inequalities in mortality have declined somewhat but there is no evidence that inequalities in deprivation have declined or that the relation between mortality and deprivation has lessened to any significant degree. Patterns of mortality and deprivation are deeply entrenched such that in both cases the patterns of a century ago are strong predictors of today's patterns. This is not simply because of inertia in socioeconomic conditions because mortality in the 1900 s is significantly related to modern mortality even when modern deprivation is taken into account. This is true of many modern causes of death, including most common cancers and circulatory and respiratory disease.

I focused on areas rather than individuals, which is both a strength and a weakness. It is a strength because the study covers the entire population; it is a limitation because it is unable to explain the patterns and, in particular, say whether they are caused by area effects or individual level behaviours. 
Table 5|Correlations between causes of death in 2001 and mortality and deprivation in 2001 and the 1900s

\begin{tabular}{|c|c|c|c|c|c|c|c|}
\hline \multirow[b]{2}{*}{ Short name } & \multirow[b]{2}{*}{ Full name (ICD code) } & \multicolumn{2}{|c|}{2001} & \multicolumn{2}{|c|}{$1900 \mathrm{~s}$} & \multicolumn{2}{|c|}{$1900 \mathrm{~s}$} \\
\hline & & SMR & Deprivation & SMR & Deprivation & $\begin{array}{c}\text { SMR } \\
\text { (partial†) }\end{array}$ & $\begin{array}{c}\text { Deprivation } \\
\text { (partial†) }\end{array}$ \\
\hline All cancers & Malignant neoplasms (C00-C97) & $0.875^{\star \star}$ & $0.429^{\star \star}$ & $0.346^{\star \star}$ & $0.279^{\star \star}$ & $0.117^{\star \star}$ & $0.042^{*}$ \\
\hline Stomach cancer & Malignant neoplasm of stomach (C16) & $0.474^{\star \star}$ & $0.379^{\star \star}$ & $0.299^{\star \star}$ & $0.231^{\star \star}$ & $0.092^{\star}$ & 0.016 \\
\hline Bowel cancer & $\begin{array}{l}\text { Malignant neoplasm of colon, rectosigmoid } \\
\text { junction, rectum, and anus (C18-C21) }\end{array}$ & $0.378^{\star \star}$ & 0.061 & $0.138^{\star \star}$ & 0.076 & $0.127^{\star \star}$ & 0.050 \\
\hline Lung cancer & $\begin{array}{l}\text { Malignant neoplasm of trachea, bronchus, } \\
\text { and lung (C33-C34) }\end{array}$ & $0.750^{\star \star}$ & $0.584^{\star \star}$ & $0.481^{\star \star}$ & $0.407^{\star \star}$ & $0.192^{\star \star}$ & $0.105^{\star \star}$ \\
\hline Breast cancer & Malignant neoplasm of breast (C50) & $0.273^{\star \star}$ & -0.013 & -0.068 & -0.019 & -0.076 & -0.014 \\
\hline Prostate cancer & Malignant neoplasm of prostate (C61) & $0.284^{\star \star}$ & 0.009 & -0.014 & -0.014 & -0.024 & -0.024 \\
\hline Diabetes & Diabetes mellitus (E10-E14) & $0.447^{\star \star}$ & $0.307^{\star \star}$ & $0.319^{\star \star}$ & $0.163^{\star \star}$ & $0.174^{\star \star}$ & -0.019 \\
\hline All heart disease & Diseases of circulatory system (100-199) & 0.930 ** & $0.390^{\star \star}$ & $0.352^{\star \star}$ & $0.146^{\star \star}$ & $0.155^{\star \star}$ & $-0.105^{\star \star}$ \\
\hline Ischaemic heart disease & Ischaemic heart disease (120-125) & $0.849^{\star \star}$ & $0.445^{\star \star}$ & $0.417^{\star \star}$ & $0.161^{\star \star}$ & $0.204^{\star \star}$ & $-0.131^{\star \star}$ \\
\hline Stroke & Cerebrovascular diseases (160-169) & $0.683^{\star \star}$ & $0.167^{\star \star}$ & $0.165^{\star \star}$ & 0.046 & $0.081^{*}$ & -0.063 \\
\hline All respiratory disease & Diseases of respiratory system (J00-J99) & $0.826^{\star \star}$ & $0.545^{\star \star}$ & $0.445^{\star \star}$ & $0.343^{\star \star}$ & $0.168^{\star \star}$ & 0.040 \\
\hline Pneumonia & Pneumonia (J12-J18) & $0.664^{\star \star}$ & $0.352^{\star \star}$ & $0.285^{\star \star}$ & $0.269^{\star \star}$ & $0.095^{*}$ & $0.086^{\star}$ \\
\hline Bronchitis, etc & $\begin{array}{l}\text { Bronchitis, emphysema, and other chronic } \\
\text { obstructive pulmonary disease (040-J44) }\end{array}$ & $0.703^{\star \star}$ & $0.577^{\star \star}$ & $0.479^{\star \star}$ & $0.379^{\star \star}$ & $0.195^{\star \star}$ & 0.069 \\
\hline Vehicle accidents & Land transport accidents (V01-V89) & 0.103 & $-0.165^{\star \star}$ & $-0.209^{* \star}$ & $-0.200^{\star \star}$ & $-0.138^{\star \star}$ & $-0.130^{\star *}$ \\
\hline
\end{tabular}

Despite these limitations, I was able to directly compare modern deprivation and mortality with conditions from a century ago for the whole of England and Wales. Previous studies have either looked at small areas such as inner London or at samples of individuals. None of them has been able to create a detailed deprivation measure for the period before the first world war. In this way I was able to present a more comprehensive look at how mortality today might have been affected by conditions in the past.

The 20th century has seen widescale reforms aimed at improving living conditions for society in general and the poor in particular. These include the formation of the National Health Service (NHS), the welfare state, regional policy, and many other initiatives. Beyond this there have been large rises in standards of living

\section{WHAT IS ALREADY KNOWN ON THIS TOPIC}

There has been a strong relation between deprivation and poverty in recent decades

There is a clear relation between poverty and mortality in inner London in the 1890 s and poverty and mortality in the $1990 \mathrm{~s}$

There is some evidence of a direct link between the social conditions in which an individual's mother or grandparents lived and their adult heath

\section{WHAT THIS STUDY ADDS}

Despite the fact that inequalities in mortality have narrowed, the relation between poverty and mortality across the whole of England and Wales seems as strong today as it was at the start of the 20th century

Mortality and deprivation patterns of 100 years ago are strong predictors of these patterns today; in particular, areas with high rates of mortality or deprivation in the past still tend to have high rates of mortality today

Even when the effects of modern deprivation are taken into account, mortality patterns from the 1900 s still have a significant relation with mortality today and this affects most major modern causes of death and huge advances in medicine and our understanding of health more generally. These have undoubtedly led to large increases in life expectancy but seem to have failed to reduce the impact that poverty has on mortality. This is not to say that these policies have been a failure as it is entirely possible that without them health inequalities might have become far worse over time. One thing that is clear is that the difficulties in reducing health inequalities should not be underestimated as these are deep rooted, long term problems.

A major unanswered question is whether the increases in mortality in deprived areas that can be ascribed to conditions in the past are caused by area effects or operate more directly at the individual level. If it is an area effect then the long term effects of the physical, economic, or social environment still seem to have a relation to modern conditions beyond those that the Carstairs index is able to measure. The strong association between modern deaths from lung cancer and 1900s mortality suggests that this might in part be a cultural effect caused by the long term prevalence of smoking in poorer areas. Individual effects are more problematic. There have been suggestions that socioeconomic conditions can have hereditary effects - for example, it has been claimed that there is a relation between mortality among Swedish men and the food supply of their paternal grandfathers. ${ }^{22}$ On a shorter time scale, the Barker hypothesis claims that poor fetal nutrition leads to heart disease, diabetes, and respiratory disorders in later life. ${ }^{2324}$ Given that deprived areas in the 1900 s are likely to still have been deprived some decades later then this could have affected people born in, for example, the 1930s who died in 2001. Clearly if either of these is occurring, migration will have had a major impact on the geographical patterns they have caused. I had no data on the 
relation between the types of areas where people died in 2001 and where they previously lived or were born or where their forebears came from. Selective migration, which suggests that migration might increase health inequalities, ${ }^{25}$ further confuses this.

The relation between mortality conditions in the 1900 s and modern rates of diabetes and respiratory and heart disease is consistent with a possible long term link to unhealthy living conditions in the distant past. On the other hand, as almost all modern causes of death show this relation this might suggest that there is a wider association that is perhaps more likely to be linked to area effects. The only way to investigate this further would be to combine an area study with information on the migrations of individuals and their forebears.

Digital boundary data for 2001 census area statistics wards were provided through EDINA (http://edina.ac.uk/) UKBorders with the support of the ESRC (Economic and Social Research Council) and JISC (Joint Information Services Committee) and use boundary material that is copyright of the Crown. The 2001 VS data were created by the Office for National Statistics and distributed by the UK Data Archive, University of Essex. Crown copyright material is reproduced with the permission of the controller of HMSO. The original data creators, depositors, or copyright holders, the funders of the data collections (if different), and the UK Data Archive bear no responsibility for their further analysis or interpretation. Census output is Crown Copyright and is reproduced with the permission of the controller of HMSO. The ArcGIS software package produced by ESRI (www.esri.com) was used to standardise the geographical units used in this study. It also assisted the analysis and produced the maps. Funding: This study was funded by the Leverhulme Trust under their early career fellowship scheme (ECF/40115).

Competing interests: None declared.

Ethical approval: Not required.

1 Registrar General's decennial supplement to the seventy-fifth annual report. Part III: Registration summary tables, 1901-1910. British Parliamentary Papers 1914-16/VIII (Cd 8002).

2 Office for National Statistics. www.statistics.gov.uk.

3 Kinsella K. Changes in life expectancy, 1900-1990. Am J Clin Nutr 1992;55:1196-202.

4 Rasulo D, Bajekal M, Yar M. Inequalities in health expectancies in England and Wales-small area analysis from the 2001 census. Health Stat Q 2007;34:35-45.
5 Rowntree BS. Poverty. A study of town life. London: MacMillan, 1901:86.

6 Townsend P. The international analysis of poverty. New York: Harvester Wheatsheaf, 1993:36.

7 Shelton N, Birkin M, Dorling D. Where not to live: a geo-demographic classification of mortality for England and Wales, 1981-2000. Health Place 2006;12:557-69.

8 Shaw M, Thomas B, Davey Smith G, Dorling D. The grim reaper's road map. Bristol: Policy Press, 2008.

9 Dorling D, Mitchell R, Shaw M, Orford S, Davey Smith G. The ghost of Christmas past: health effects of poverty in London in 1896 and 1991. BMJ 2000;321:1547-51.

10 Office for National Statistics. Vital statistics for England and Wales, 2001. Colchester, Essex: UK Data Archive, 2002.

11 Office for National Statistics. Census: standard area statistics (England and Wales), 2001. Manchester: ESRC/IISC Census Programme, Census Dissemination Unit, Mimas (University of Manchester).

12 County Reports from the 1901 Census, British Parliamentary Papers: 1902 CXVIII to CXXI and 1903 LXXXIV to LXXXVI.

131911 Census Report. Volume VII. Ages and condition as to marriage. London: National Archives (British Parliamentary Papers 1912-13 (XIII.)

14 Morris R, Carstairs V. Which deprivation? A comparison of selected deprivation indexes. J Public Health Med 1991;13:318-25.

15 Morgan O, Baker A. Measuring deprivation in England and Wales using 2001 Carstairs scores. Health Stat Q 2006;31:28-33.

16 Davey Smith G, Dorling D, Mitchell R, Shaw M. Health inequalities in Britain: continuing increases up to the end of the 20th century. I Epidemiol Community Health 2002;56:434-35.

17 Shaw M, Dorling D, Gordon D, Davey Smith G. The widening gap: health inequalities and policy in Britain. 2nd ed. Bristol: Policy Press, 2000.

18 Gregory IN, Dorling D, Southall HR. A century of inequality in England and Wales using standardised geographical units. Area 2001;33:297-311.

19 Gregory IN, Bennett C, Gilham VL, Southall HR. The Great Britain historical GIS: from maps to changing human geography. Cartographic / 2002;39:37-49. See also: www.gbhgis.org.

20 Gregory IN, Ell PS. Breaking the boundaries: integrating 200 years of the census using GIS. J Roy Stat Soc Ser A 2005;168:419-37.

21 Norman P. Micro-geography of UK demographic change 1991-2001. ESRC programme Understanding Population Trends and Processes 2007; RES-163-25-0012.

22 Pembrey ME, Bygren LO, Kaati G, Edvinsson S, Northstone K, Sjostrom $\mathrm{M}$, et al. Sex-specific, male-line transgenerational responses in humans. Eur J Hum Genet 2006;14:159-66.

23 Barker DJB, ed. Fetal and infant origins of adult disease. London: B MJ Publishing, 1992.

24 Barker DJB. Mothers, babies, and diseases in later life. London: B MJ Publishing, 1994.

25 Norman P, Boyle P, Rees P. Selective migration, health and deprivation: a longitudinal analysis. Soc Sci Med 2005;60:2755-71.

Accepted: 24 March 2009 